DOE/ER/13725-6

DE93 004640

\title{
SOLID STATE. SURFACE AND CATALYTIC STUDIES OF OXIDES
}

\author{
Annual Progress Report
}

For the period January 1, 1992 to December 31, 1992

\author{
Harold H. Kung
}

Chemical Engineering Department

Northwestern University

Evanston, Illinois 60208-3120

December 7, 1992

Prepared for

The U.S. Department of Energy AGREEMENT NO. DE-FG02-87ER13725

File:921207 
NOT ICE

This report was prepared as an account of work sponsored by the United States Government. Neither the United States nor the Department of Energy, nor any of their employees, nor any of their contractors, subcontractors, or their employees, makes any warranty, express or implied, or assumes any legal liability or responsibility for the accuracy, completeness, or usefulness of any information, apparatus, product or process disclosed or represents that its use would not infringe privately-owned rights. 


\begin{abstract}
The properties of oxide catalysts that determine selectivity in the oxidation of alkanes have been investigated. Upon examining the product distribution in the oxidation of ethane, propane, butane, pentane, and cyclohexane over $\mathrm{Mg}$ orthovanadate, $\mathrm{Mg}$ pyrovanadate, and vanadyl pyrophosphate, it was found that whether dehydrogenation, formation of oxygen-containing organic products, or combustion was the predominant reaction depended on the catalyst and the alkane. The pattern of product distribution could be explained by considering whether the active sites contained easily removable lattice oxygen ions, and whether the size of the alkane molecule was sufficient large to be bonded to two adjacent vanadium ions in the active site in a manner that would enhance the probability of reaction between the adsorbed hydrocarbon intermediate and the reactive lattice oxygen.
\end{abstract}

It was observed that the selectivity for oxidative dehydrogenation of butane on silicasupported vanadium oxide depended on the vanadia loading. The selectivity was much higher on a $1 \mathrm{wt} . \%$ than on a $10 \mathrm{wt} . \% \mathrm{~V}_{2} \mathrm{O}_{5} / \mathrm{SiO}_{2}$ sample. It was also found that on the 10 wt.\% sample, agglomeration of vanadia into $\mathrm{V}_{2} \mathrm{O}_{5}$ crystallites occurred during reaction. The results suggested that isolated $\mathrm{VO}_{4}$ units were more selective for dehydrogenation of butane, consistent with the idea that the selectivity depended on the availability of reactive oxygen in the active site.

\title{
INTRODUCTION
}

Selective oxidation of light alkanes is a potentially important route to convert the less valuable alkanes to more valuable chemicals such as unsaturated hydrocarbons and oxygenated compounds that are used in fuel mixtures and as feedstock. In specific operations, such processes can also be used to remove environmentally hostile chemicals while converting them into useful chemicals. For such processes to be commercially practical, high yields of the desired products must be obtained instead of the thermodynamically most favored products of carbon oxides. The objective of this research is to develop understandings regarding the interaction of molecules with catalytic surfaces and the relationship between the buik and surface properties of oxides that would lead to the discovery of highly selective catalysts.

\section{OBJECTIVES FOR THIS PERIOD}

Work conducted in this period can be grouped into two projects, both of which are continuation of previous effort that deals with selective oxidation of alkanes. They are:

1) Investigation of the dependence of selectivity in the catalytic oxidation of $C_{2}$ to $C_{6}$ alkanes on the bonding characteristics of $\mathrm{VO}_{\mathrm{x}}$ units in vanadate catalysts. 
2) Investigation of the effect of $\mathrm{SiO}_{2}$ and $\mathrm{Al}_{2} \mathrm{O}_{3}$ support on the oxidative dehydrogenation of butane and pentane.

\section{PROGRESS}

\section{Project 1: Relationship between selectivity in alkane oxidation and the bonding characteristics in vanadate catalysts.}

In the last progress report submitted in December, 1991, we reported that we have collected data on the product distributions in the oxidation of ethane, propane, 2methylpropane, butane, pentane, and cyclohexane over three catalysts based on vanadium oxide, which were magnesium orthovanadate $\left(\mathrm{Mg}_{3}\left(\mathrm{VO}_{4}\right)_{2}\right)$, magnesium pyrovanadate $\left(\mathrm{Mg}_{2} \mathrm{~V}_{2} \mathrm{O}_{7}\right)$, and vanadyl pyrophosphate $(\mathrm{VO})_{2} \mathrm{P}_{2} \mathrm{O}_{7}$. Some typical product distributions are shown in Table 1. In general, at low alkane conversions, $\mathrm{Mg}$ orthovanadate is quite selective for oxidative dehydrogenation of these alkanes except ethane, whereas $\mathrm{Mg}$ pyrovanadate is quite nonselective except for propane for which dehydrogenation is the dominant product, and vanadyl pyrophosphate is selective in a number of ways: dehydrogenation for ethane, and oxygenate formation for butane and pentane. Effort was spent to interpret these selectivity patterns.

The following model was finally arrived at. The active sites of these catalysts are assumed to be $V \mathrm{VO}_{\mathrm{x}}$ units. These $\mathrm{VO}_{\mathrm{x}}$ units are shown in Fig. 1. The active sites on $\mathrm{Mg}_{3}\left(\mathrm{VO}_{4}\right)_{2}$ are isolated $\mathrm{VO}_{4}$ tetrahedra such that all the oxygen ions are bridged between a $\mathrm{V}$ and a $\mathrm{Mg}$ ion. For $\mathrm{Mg}_{2} \mathrm{~V}_{2} \mathrm{O}_{7}$, the active sites are $\mathrm{V}_{2} \mathrm{O}_{7}$ units that can be viewed as pairs of corner-sharing $\mathrm{VO}_{4}$ tetrahedra. For the VPO catalyst, they are assumed to be $\mathrm{V}_{2} \mathrm{O}_{8}$ units made up of pairs of distorted edge-sharing $\mathrm{VO}_{5}$ square pyramids. The assumption of these active sites, especially for the VPO catalyst, was discussed in the paper accepted for publication in the Journal of Catalysis [1]. Since $\mathrm{Mg}$ is not easily reducible, this model implies that there are easily removable oxygen atoms in the active sites of $\mathrm{Mg}_{2} \mathrm{~V}_{2} \mathrm{O}_{7}$ and $(\mathrm{VO})_{2} \mathrm{P}_{2} \mathrm{O}_{7}$, but not in $\mathrm{Mg}_{3}\left(\mathrm{VO}_{4}\right)_{2}$.

After the first $\mathrm{C}-\mathrm{H}$ bond of an alkane is broken, a surface alkyl species is formed. There are at least two possible reactions for this alkyl species that lead to different products. Dehydrogenation products would be formed if the alkyl species reacts by breaking another $\mathrm{C}-\mathrm{H}$ bond at the $\mathrm{B}$-position. Alternatively, the alkyl species may react not only by breaking a $\mathrm{C}-\mathrm{H}$ bond, but also by forming a $\mathrm{C}-\mathrm{O}$ bond. Since it is likely that the formation of a $\mathrm{C}-\mathrm{O}$ bond is irreversible, depending on whether the surface alkyl species reacts by forming a $\mathrm{r}-\mathrm{O}$ bond or not, oxygen-containing (including organic products and $\mathrm{CO}_{\mathbf{x}}$ ) or dehydrogenation products would be formed. Thus one can view the reaction of the alkyl species as a selectivity-determining step, and the ease of removal of an oxygen atom from the lattice to form a $\mathrm{C}-\mathrm{O}$ bond with the surface intermediate should be an important factor that determines the selectivity of the reaction. This is represented by the following scheme: 


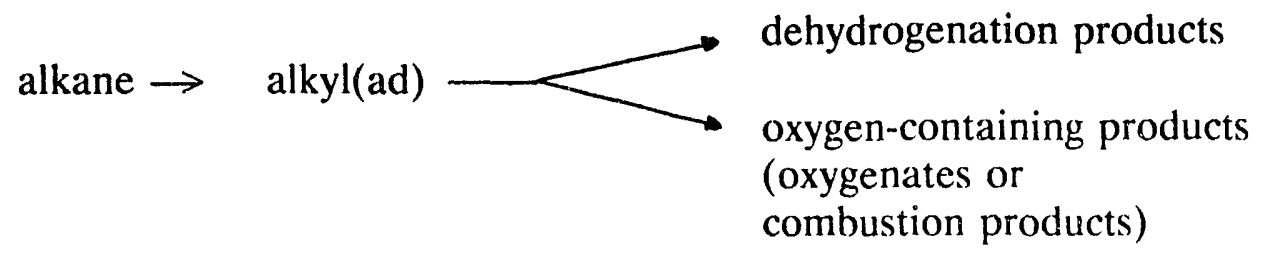

Alternatively, the selectivity-determining step could be the reaction of an adsorbed alkene formed from a surface alkyl (i.e., not by readsorption). In that case, dehydrogenation products are observed if the alkene desorbs, and oxygen-containing products are observed if it reacts further with a lattice oxygen, such as by insertion of a lattice oxygen into a $\mathrm{C}=\mathrm{C}$ bond.

Within the scheme presented above, the products in Table 1 can be grouped into dehydrogenation or oxygen-containing products. It is apparent that the ease of removal of lattice oxygen (or reducibility of the cations) can be used as a factor that explains most of the data, that is, oxides in which the lattice oxygen can be easily removed tend to produce mostly oxygen-containing products, whereas those that do not are more selective dehydrogenation catalysts. However, it is also apparent that this factor alone is insufficient to explain all of the data. $\mathrm{Mg}_{3}\left(\mathrm{VO}_{4}\right)_{2}$ is indeed a selective dehydrogenation catalyst for most of the alkanes studied, whereas $\mathrm{Mg}_{2} \mathrm{~V}_{2} \mathrm{O}_{7}$ and (VO) ${ }_{2} \mathrm{P}_{2} \mathrm{O}_{7}$ produce mostly oxygencontaining products. However, contrary to expectation, propane reacts on $\mathrm{Mg}_{2} \mathrm{~V}_{2} \mathrm{O}_{7}$ with a high dehydrogenation selectivity, whereas ethane reacts with high dehydrogenation selectivity on (VO) ${ }_{2} \mathrm{P}_{2} \mathrm{O}_{7}$, but with mostly combustion on $\mathrm{Mg}_{3}\left(\mathrm{VO}_{4}\right)_{2}$.

In order to explain a broader range of data, in addition to the necessary condition of possessing readily removable lattice oxygen in the active site, another condition is needed that the formation of oxygen-containing products is enhanced if the hydrocarbon intermediate in the selectivity-determining step can be bonded to the two vanadium ions of the linked $\mathrm{VO}_{\mathrm{x}}$ units such that the hydrocarbon species is being held close to the surface reactive lattice oxygen. This latter requirement could be met only if the molecule is sufficiently large to do so. Whether this condition is satisfied or not can be examined by comparing the molecular size with the separation of the vanadium ions in the active sites. When this additional factor is taken into account, the data for propane and 2-methylpropane can be explained.

The behavior of ethane is different from the other alkanes. It is the only alkane that undergoes significant dehydrogenation on the VPO catalyst, as well as the only one for which combustion is the predominant reaction on $\mathrm{V}-\mathrm{Mg}-\mathrm{O}$. An ethyl species is too small to interact with two $\mathrm{V}$ ions simultaneously on any of the three catalysts. A phenomenological explanation of this behavior of ethane was suggested [1]. 
Project 2: Effect of support and vanadia loading on the selectivity in the oxidation of butane and pentane on supported vanadia catalysts.

Recently we have been working with the hypothesis that the selectivity of an oxidation catalyst is determined by two properties of the active site: the ease of removal of oxygen of the site (i.e. reducibility of the cation), and the number of removable oxygen atoms available to the reacting molecule. Whereas these are not new ideas (see e.g. a review of these concepts in H. Kung, Ind. Eng. Chem. Prod. Res. Devel., 25, 171 (1986)), we make use of them to postulate that the selectivity for butane oxidation on supported vanadia catalysts should depend on the dispersion of vanadia.

We tested our postulate using $\mathrm{SiO}_{2}$ and $\mathrm{Al}_{2} \mathrm{O}_{3}$-supported vanadia. It is known in the literature that at low loadings on $\mathrm{SiO}_{2}$, the vanadium oxide exists as isolated $(*-\mathrm{O}-)_{3} \mathrm{~V}=\mathrm{O}$ species, and as crystallites of $\mathrm{V}_{2} \mathrm{O}_{5}$ at high loadings. On alumina, vanadia at low loadings exists both as isolated (*-O- $)_{3} \mathrm{~V}=\mathrm{O}$ and polymeric species, and probably three-dimensional network and crystalline $\mathrm{V}_{2} \mathrm{O}_{5}$ at high loadings. These structures can be monitored qualitatively with laser Raman spectroscopy. Fig. 2 shows the Raman spectra for four samples: two silica-supported samples of 1 and $10 \mathrm{wt} \% \mathrm{~V}_{2} \mathrm{O}_{5}$, and two alumina-supported samples of 8.2 and $23.4 \mathrm{wt} . \% \mathrm{~V}_{2} \mathrm{O}_{5}$. The spectra of the two silica samples can be explained by the presence of two vanadia species: the isolated species $(*-\mathrm{O}-)_{3} \mathrm{~V}=\mathrm{O}$ characterized by the $1030 \mathrm{~cm}^{-1}$ peak and crystalline vanadia $\left(\mathrm{V}_{2} \mathrm{O}_{5}\right)$ characterized by the $998 \mathrm{~cm}^{-1}$ peak. The alumina samples, however, show additional Raman bands in the $800-950 \mathrm{~cm}^{-1}$ region that are most likely due to polymeric $\mathrm{VO}_{\mathrm{x}}$ units [2]. The structures of these polymeric units are unknown, but the different Raman peak shapes suggest differences for samples of different loadings.

The catalytic properties of these four samples in butane and pentane oxidation are being investigated. Fig. 3 shows the selectivity for dehydrogenation to butenes and butadiene in butane oxidation over the $\mathrm{V} / \mathrm{SiO}_{2}$ catalysts. It shows clearly that over the range of butane conversions studied, the $1 \mathrm{wt} \%$ sample is much more selective for dehydrogenation than the $10 \mathrm{wt} . \%$ sample. The activation energy for the reaction also differs, being $110 \mathrm{~kJ} /$ mole on the lower loading sample, and $170 \mathrm{~kJ} /$ mole for the higher loading sample. Interestingly, however, the rates of reaction, estimated on the basis of moles of butane converted per mole of $\mathrm{V}$ in the sample, differ by less than a factor of ten for the two samples.

In the course of this study, we have also shown that the fraction of vanadia present as isolated species or crystalline $\mathrm{V}_{2} \mathrm{O}_{5}$ on the silica support depends on the source of silica and the history of the sample. Fig. $4 \mathrm{a}$ and $\mathrm{c}$ show the Raman spectra of $10 \mathrm{wt} \% \mathrm{~V}_{2} \mathrm{O}_{5}$ supported on acid-washed Davison silica and Cabosil silica, respectively, before they were used in the reaction. (Acid-wash was to remove impurities in the Davison silica, particularly $\mathrm{Na}$ and $\mathrm{Ca})$. Both spectra show the presence of both isolated $(*-\mathrm{O}-)_{3} \mathrm{~V}=\mathrm{O}\left(1030 \mathrm{~cm}^{-1}\right.$ peak) and $\mathrm{V}_{2} \mathrm{O}_{5}\left(998 \mathrm{~cm}^{-1}\right.$ peak $)$, but the fraction of vanadia being the isolated species is larger on the Cabosil support than on the acid-washed Davison silica support, as indicated 
by the relative intensities of the two Raman peaks. Fig. 4b and d show the spectra of these two samples after being used in butane oxidation, cooled in the reaction mixture and loaded into the Raman spectrometer without exposure to air. Compared to Fig. 4a and c, the samples after reaction show decreased intensities of the $1030 \mathrm{~cm}^{-1}$ peak relatively to the 998 $\mathrm{cm}^{-1}$ peak. These results indicate that migration of vanadia species occurs on the silica surface resulting in agglomeration, either under reaction conditions or during cooling in the reaction mixture. These results point to the importance of obtaining structural information under reaction conditions.

The results thus far on the $\mathrm{SiO}_{2}$-supported samples indicate that the isolated $(*-\mathrm{O}-)_{3} \mathrm{~V}=\mathrm{O}$ species is much more selective for oxidative dehydrogenation of butane than crystalline $\mathrm{V}_{2} \mathrm{O}_{5}$. Our current interpretation is that this is due to the much smaller number of oxygen atoms available in the isolated species during one catalytic cycle than that available for active sites on the $\mathrm{V}_{2} \mathrm{O}_{5}$ surface, because lattice diffusion is possible for the latter species. The other possible interpretation that it is more difficult to reduce the $(*-\mathrm{O}-)_{3} \mathrm{~V}=\mathrm{O}$ species is rejected because it is opposite to the observation in temperature programmed reduction (TPR). TPR shows that the on-set temperature of reduction of the lower loading sample is lower than the higher loading sample $[3$, also confirmed in our measurements]. It is interesting to point out that our observations about selectivity for dehydrogenation in butane oxidation is different from the results reported for ethane oxidation [4], which show that the lower loading samples were less selective.

Preliminary reports of these findings have been presented in the Washington ACS meeting in August, 1992 [5], and the Miami Beach AIChE meeting in November, 1992. A manuscript is under preparation.

The oxidation of pentane is being studied over these four catalysts for comparison with the result of butane oxidation. The results of our earlier work, which are shown in Table 1, indicate that butane and pentane could show interesting differences. In particular, a higher carbon number product, phthalic anhydride could be formed. Thus the pentane oxidation reaction provides an opportunity to study carbon-carbon bond formation under oxidation conditions.

The preliminary results of pentane oxidation over supported vanadia samples are shown in Table 2. These data for butane and pentane oxidation show that the nature of the products (in terms of dehydrogenation, oxygen and combustion products, and products of $\mathrm{C}-\mathrm{C}$ bond formation) depends on both the support, the vanadium loading and the alkane. Although many more experiments need to be conducted to obtain results for comparison under comparable conditions, these preliminary data show that this direction of research provides a promising lead to generate understanding regarding the relationship among properties of the active site and product selectivity. We plan to continue with this study. 


\section{REFERENCES}

1) P. Michalakos, M. Kung, I. Jahan, and H. Kung, J. Catal., accepted.

2) G.T. Went, S.T. Oyama, and A.T. Bell, J. Phys. Chem., 94, 4240 (1990).

3) F. Roozebaum, M. Mittelmeijer-Hezeleger, J. Moulijn, J. Medema, V. deBeer, and P. Gellings, J. Phys. Chem., 84, 2783 (1980).

4) S.T. Oyama, and G.A. Somorjai, J. Phys. Chem., 94, 5022 (1990).

5) L. Owens, and H. Kung, ACS Div. Petrol Chem. Prepr., 37, 1194 (1992).

\section{PUBLICATIONS APPEARED OR SUBMITTED IN THIS PERIOD}

1) "Deactivation of Methanol Synthesis Catalysts - a Review," H.H. Kung, Catalysis Today, 11, 443 (1992).

2) "The Effect of Oxide Structure and Cation Reduction Potential of Vanadates on the Selective Oxidative Dehydrogenation of Butane and Propane," O.S. Owen, M.C. Kung, and H.H. Kung, Catal. Lett., 12, 45 (1992).

3) "Kinetic Analysis of a Generalized Catalytic Selective Oxidation Reaction," H.H. Kung, J. Catal., 134, 691 (1992).

4) "The Effect of Potassium in the Preparation of Mg Orthovanadate and Pyrovanadte on the Oxidative Dehydrogenation of Propane and Butane," M.C. Kung, and H.H. Kung, J. Catal., 134, 668 (1992).

5) "A Kinetic Model oî the Epoxidation of Ethylene," H.H. Kung, Chem. Eng. Commun., accepted.

6) "The Effect of Water on the Oxidation of 2-Butanone on Vanadium Oxide," I. Jahan, and H.H. Kung, Ind. and Eng. Chem. Res., 31, 2328 (1992).

7) "Effects of Loading and Cesium Modifier on Silica-Supported Vanadia in Oxidative Dehydrogenation of Butane," L. Owens, and H.H. Kung, Prepr. ACS Div. Petrol. Chem., 37, 1194 (1992).

8) "A Comparison of $\mathrm{Mg}_{3}\left(\mathrm{VO}_{4}\right)_{2}, \mathrm{Mg}_{2} \mathrm{~V}_{2} \mathrm{O}_{7}$, and $(\mathrm{VO})_{2} \mathrm{P}_{2} \mathrm{O}_{7}$ in Alkane Oxidation," P.M. Michalakos, M.C. Kung, I. Jahan, and H.H. Kung, Prepr. ACS Div. Petrol. Chem., 37, 1201 (1992).

9) "Selectivity Patterns in Alkane Oxidation over $\mathrm{Mg}_{3}\left(\mathrm{VO}_{4}\right)_{2}, \mathrm{Mg}_{2} \mathrm{~V}_{2} \mathrm{O}_{7}$, and (VO) ${ }_{2} \mathrm{P}_{2} \mathrm{O}_{7}$," P.M. Michalakos, M.C. Kung, I. Jahan, and H.H. Kung, J. Catal., accepted.

10) "The Effect of Cation Reducibility on the Oxidative Dehydrogenation of 
Butane in Orthovanadates," Ozie S. Owen and Harold H. Kung, J. Molec. Catal., accepted.

11) "Factors that Determine Selectivity for Dehydrogenation in the Oxidation of Light Alkanes," H.H. Kung, P. Michalakos, L. Owens, M. Kung, P. Andersen, O. Owen, and I. Jahan, accepted.

12) "Oxidative Dehydrogenation of Light $\left(\mathrm{C}_{2}-\mathrm{C}_{6}\right)$ Alkanes," H. H. Kung, Adv. Catal., accepted. 
Table 1. Typical Product Distributions for Alkane Oxidation on V-Mg Oxide $\left(\mathrm{Mg}_{3}\left(\mathrm{VO}_{4}\right)_{2}\right.$ $\mathrm{MgO}), \mathrm{Mg}_{2} \mathrm{~V}_{2} \mathrm{O}_{7}$, and VPO ((VO) $\left.)_{2} \mathrm{P}_{2} \mathrm{O}_{7}\right)$.

\begin{tabular}{|c|c|c|c|c|c|c|c|c|c|}
\hline Reactant & $\begin{array}{c}\operatorname{Rxn} T \\
\left({ }^{\circ} \mathrm{C}\right)\end{array}$ & $\begin{array}{l}\text { Alkane } \\
\text { conv. } \%\end{array}$ & \multicolumn{3}{|c|}{$\%$ Selectivity ${ }^{a}$} & & & & \\
\hline \multicolumn{3}{|c|}{ Qver VPO catalyst } & & & & & & & \\
\hline $\mathrm{C}_{2} \mathrm{H}_{6}$ & 305 & 3.8 & $\frac{\mathrm{CO}}{12}$ & $\frac{\mathrm{CO}_{2}}{7}$ & $\frac{\mathrm{C}_{2} \mathrm{H}_{4}}{81}$ & & & & \\
\hline $\mathrm{C}_{3} \mathrm{H}_{8}$ & 300 & 8 & $\frac{\mathrm{CO}}{62}$ & $\frac{\mathrm{CO}_{2}}{26}$ & $\frac{\mathrm{C}_{2} \mathrm{H}_{4}}{4}$ & $\frac{\mathrm{C}_{3} \mathrm{H}_{6}}{0}$ & $\frac{A c}{6}$ & $\frac{\mathrm{Ar}}{2}$ & \\
\hline $\mathrm{C}_{4} \mathrm{H}_{10}$ & 300 & 7 & $\frac{C O}{16}$ & $\frac{\mathrm{CO}_{2}}{10}$ & $\frac{\mathrm{C}_{2} \mathrm{H}_{4}}{2}$ & $\underline{\mathrm{C}}_{3} \underline{\mathrm{H}}_{6}$ & $\frac{A c}{7}$ & $\frac{A_{T}}{2}$ & $\frac{\mathrm{MA}}{64}$ \\
\hline $\mathrm{C}_{5} \mathrm{H}_{12}$ & 325 & 7 & $\frac{\mathrm{CO}}{22}$ & $\frac{\mathrm{CO}_{2}}{15}$ & $\frac{\mathrm{MA}}{19}$ & $\frac{\mathrm{PA}}{44}$ & & & \\
\hline
\end{tabular}

Over V-Mg-O catalyst

\begin{tabular}{|c|c|c|c|c|c|}
\hline $\mathrm{C}_{2} \mathrm{H}_{6}$ & 540 & 5.2 & $\frac{\mathrm{CO}}{28}$ & $\frac{\mathrm{CO}_{2}}{49}$ & $\frac{\mathrm{C}_{2} \mathrm{H}_{4}}{24}$ \\
\hline $\mathrm{C}_{3} \mathrm{H}_{8}$ & 500 & 8.4 & $\frac{\mathrm{CO}}{14}$ & $\frac{\mathrm{CO}_{2}}{24}$ & $\frac{\mathrm{C}_{3} \mathrm{H}_{6}}{62}$ \\
\hline $\mathrm{iC}_{4} \mathrm{H}_{10}$ & 475 & 4.0 & $\frac{C O}{7}$ & $\frac{\mathrm{CO}_{2}}{22}$ & $\frac{\mathrm{C}_{4} \mathrm{H}_{8}}{71}$ \\
\hline $\mathrm{C}_{4} \mathrm{H}_{10}$ & 475 & 4.1 & $\frac{\mathrm{CO}}{9}$ & $\frac{\mathrm{CO}_{2}}{22}$ & $\frac{\mathrm{C}_{4} \mathrm{H}_{8}}{55}$ \\
\hline $\mathrm{cC}_{6} \mathrm{H}_{12}$ & 484 & 8.4 & $\frac{\mathrm{CO}}{3}$ & $\frac{\mathrm{CO}_{2}}{14}$ & $\frac{\mathrm{C}_{6} \mathrm{H}_{10}}{47}$ \\
\hline
\end{tabular}

Over $\mathrm{Mg}_{2} \mathrm{~V}_{2} \mathrm{O}_{7}$ catalyst

\begin{tabular}{|c|c|c|c|c|c|}
\hline $\mathrm{C}_{2} \mathrm{H}_{6}$ & 540 & 3.2 & $\frac{\mathrm{CO}}{49}$ & $\frac{\mathrm{CO}_{2}}{21}$ & $\frac{\mathrm{C}_{2} 2 \mathrm{H}_{4}}{30}$ \\
\hline $\mathrm{C}_{3} \mathrm{H}_{8}$ & 475 & 10 & $\frac{\mathrm{CO}}{27}$ & $\frac{\mathrm{CO}_{2}}{18}$ & $\frac{\mathrm{C}_{3} \mathrm{H}_{6}}{56}$ \\
\hline $\mathrm{iC}_{4} \mathrm{H}_{10}$ & 502 & 6.8 & $\frac{\mathrm{CO}}{39}$ & $\frac{\mathrm{CO}_{2}}{36}$ & $\frac{\mathrm{C}_{4} \mathrm{H}_{8}}{25}$ \\
\hline $\mathrm{C}_{4} \mathrm{H}_{10}$ & 500 & 6.8 & $\frac{\mathrm{CO}}{33}$ & $\frac{\mathrm{CO}_{2}}{33}$ & $\frac{\mathrm{C}_{4} \mathrm{H}_{8}}{31} \frac{\mathrm{C}_{4} \mathrm{H}_{6}}{2}$ \\
\hline
\end{tabular}

a) $\mathrm{Ac}=$ acetic acid, $\mathrm{Ar}=$ acrylic acid, $\mathrm{MA}=$ maleic anhydride, $\mathrm{PA}=$ phthalic anhydride. 
Table 2: Product distributions in the oxidation of butane and pentane.

Catalyst Conv $\% \quad \frac{\text { Product distribution (\% selectivity) }}{\text { Dehydrog. MA PA CO } \text { D }_{x} \text { others }}$

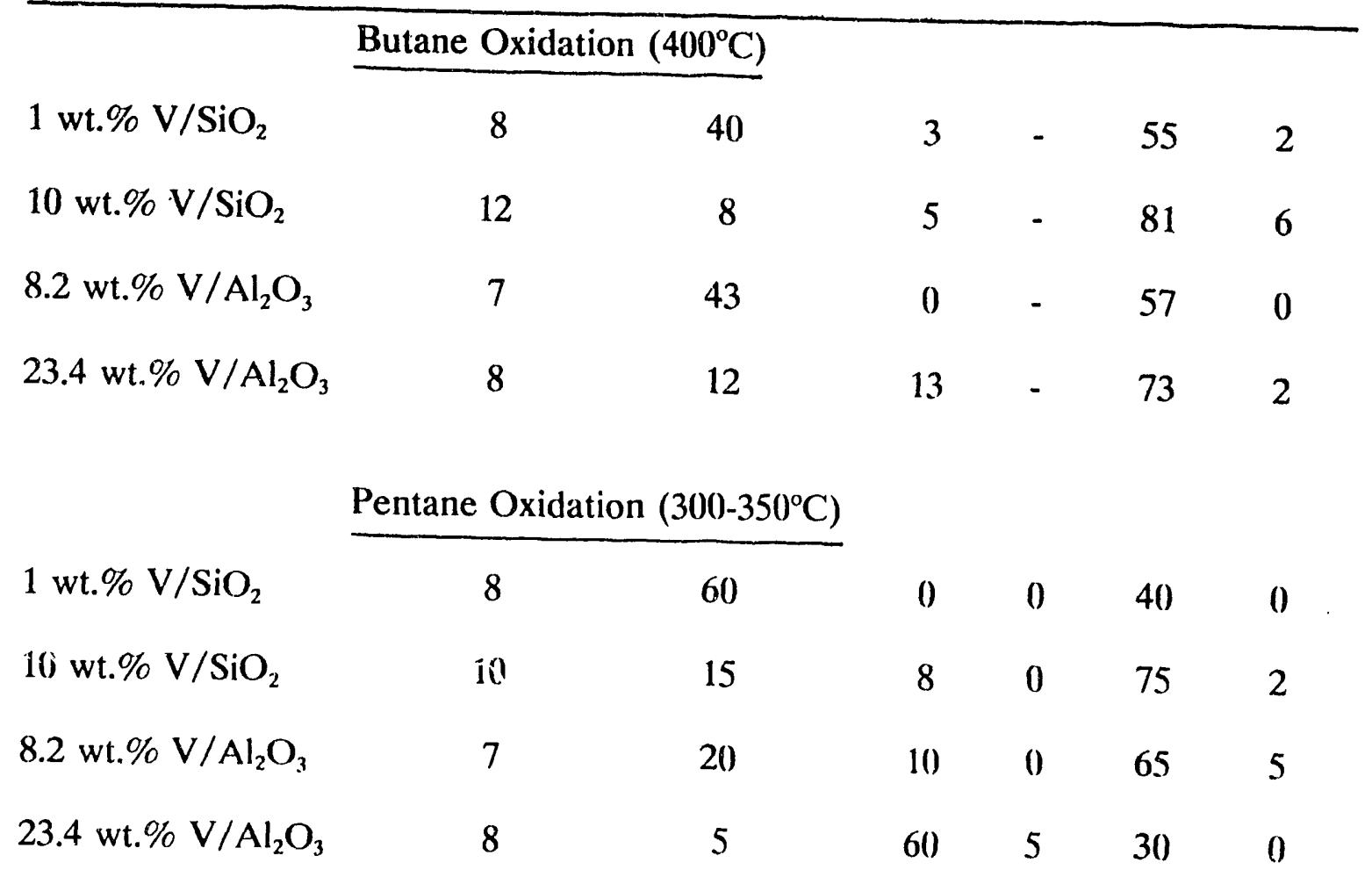




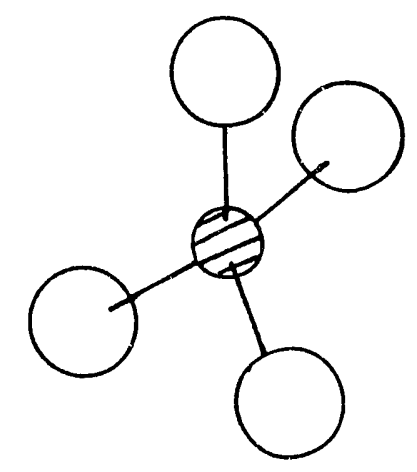

$\mathbf{A}$

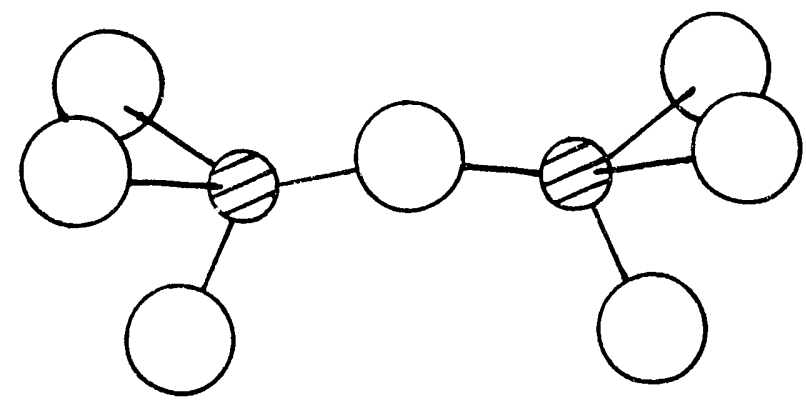

B

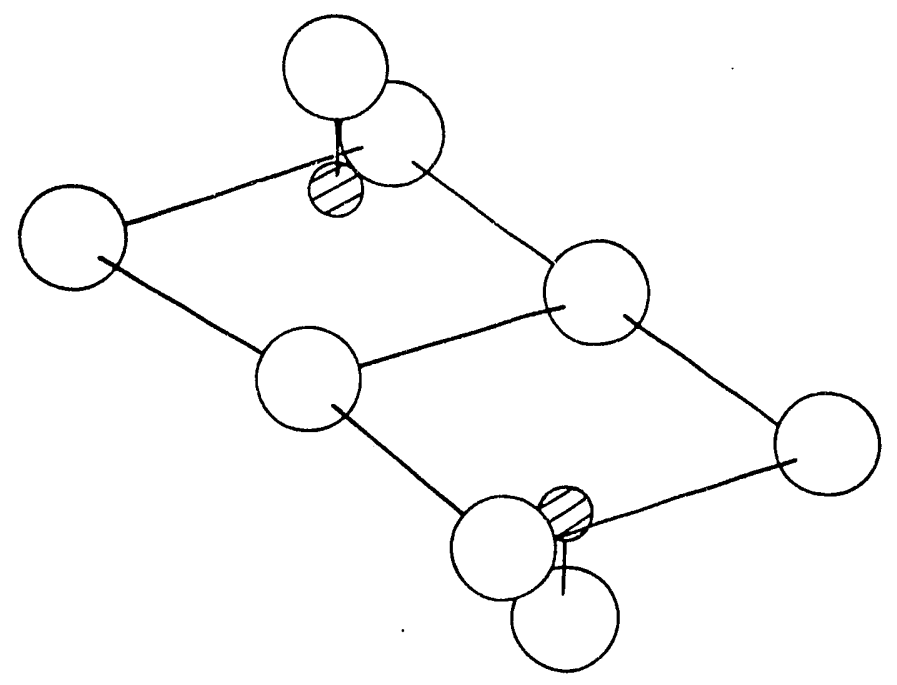

C

Fig. 1: Models of active sites. (A) Isolated $\mathrm{VO}_{4}$ unit in $\mathrm{Mg}_{3}\left(\mathrm{VO}_{4}\right)_{2}$.

(B) Cornersharing $\mathrm{VO}_{4}$ units in $\mathrm{Mg}_{2} \mathrm{~V}_{2} \mathrm{O}_{7}$.

(C) Edge-sharing $\mathrm{VO}_{5}$ units in

(VO) ${ }_{2} \mathrm{P}_{2} \mathrm{O}_{7}$. 
A)

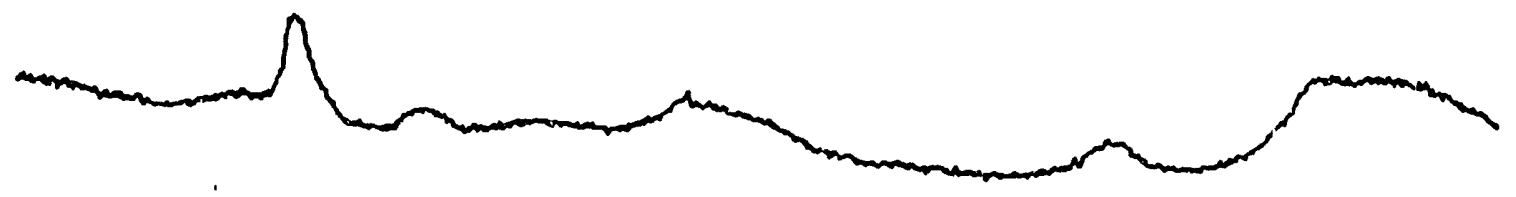

B)
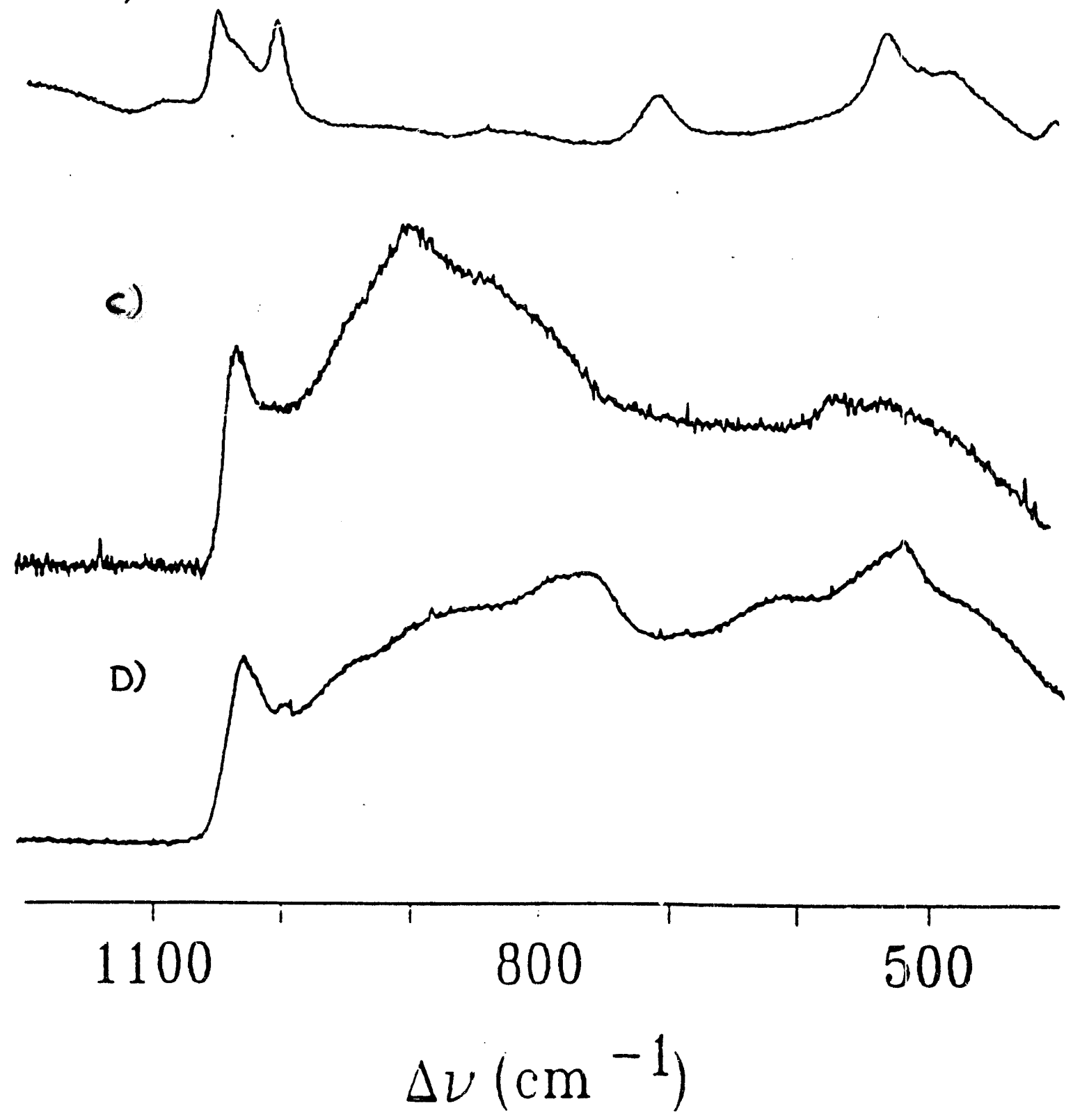

Fig. 2: Raman spectra of (a) 1 wt. $\% \mathrm{v}_{2} \mathrm{O}_{5} / \mathrm{SiO}_{2}$, (b) $10 \mathrm{wt} . \% \mathrm{v}_{2} \mathrm{O}_{5} / \mathrm{SiO}_{2}$, (c) 1 wt.\% $\mathrm{V}_{2} \mathrm{O}_{5} / \mathrm{Al}_{2} \mathrm{O}_{3}$, and (d) $10 \mathrm{wt} \% \mathrm{v}_{2} \mathrm{O}_{5} / \mathrm{Al}_{2} \mathrm{O}_{3}$. 


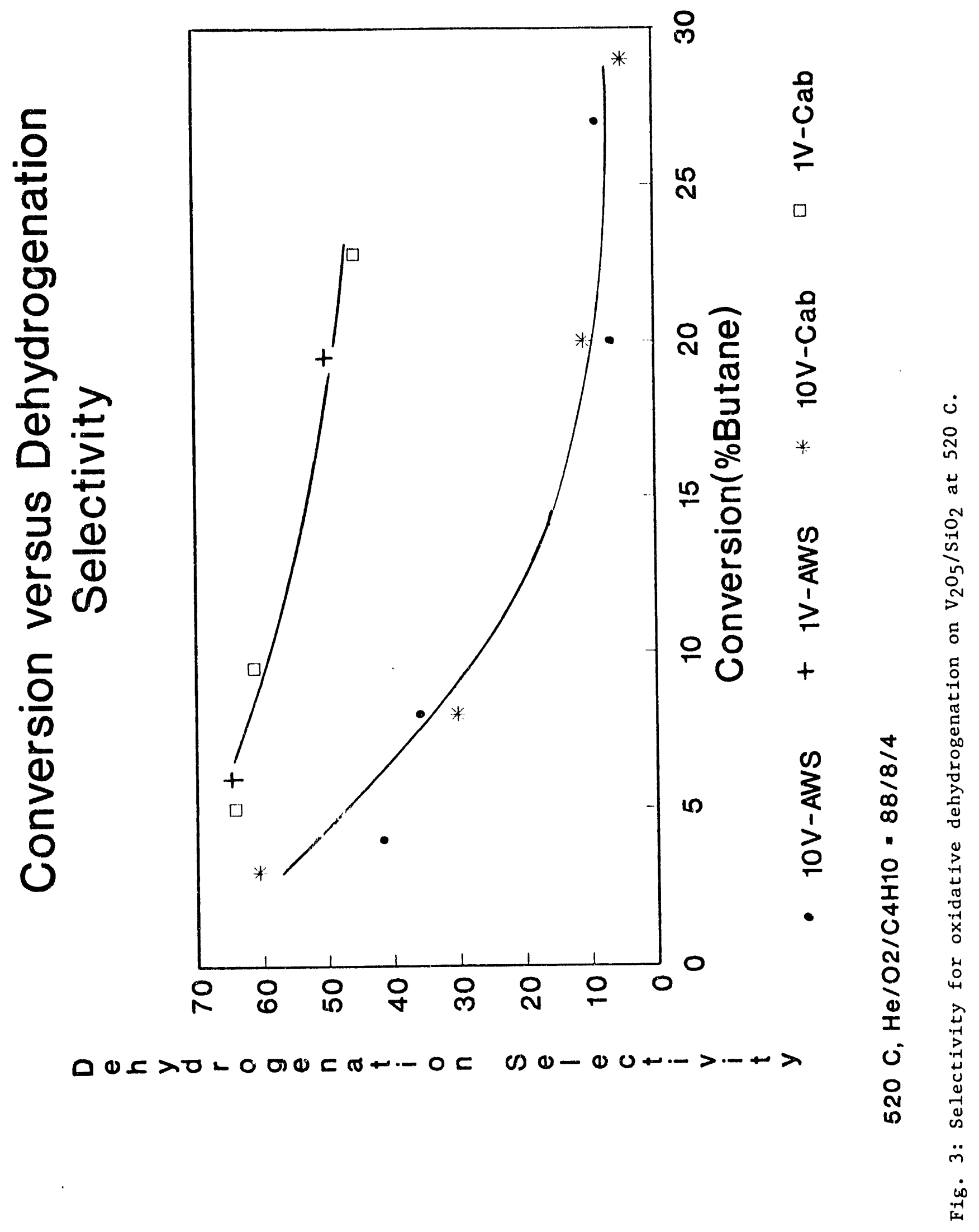




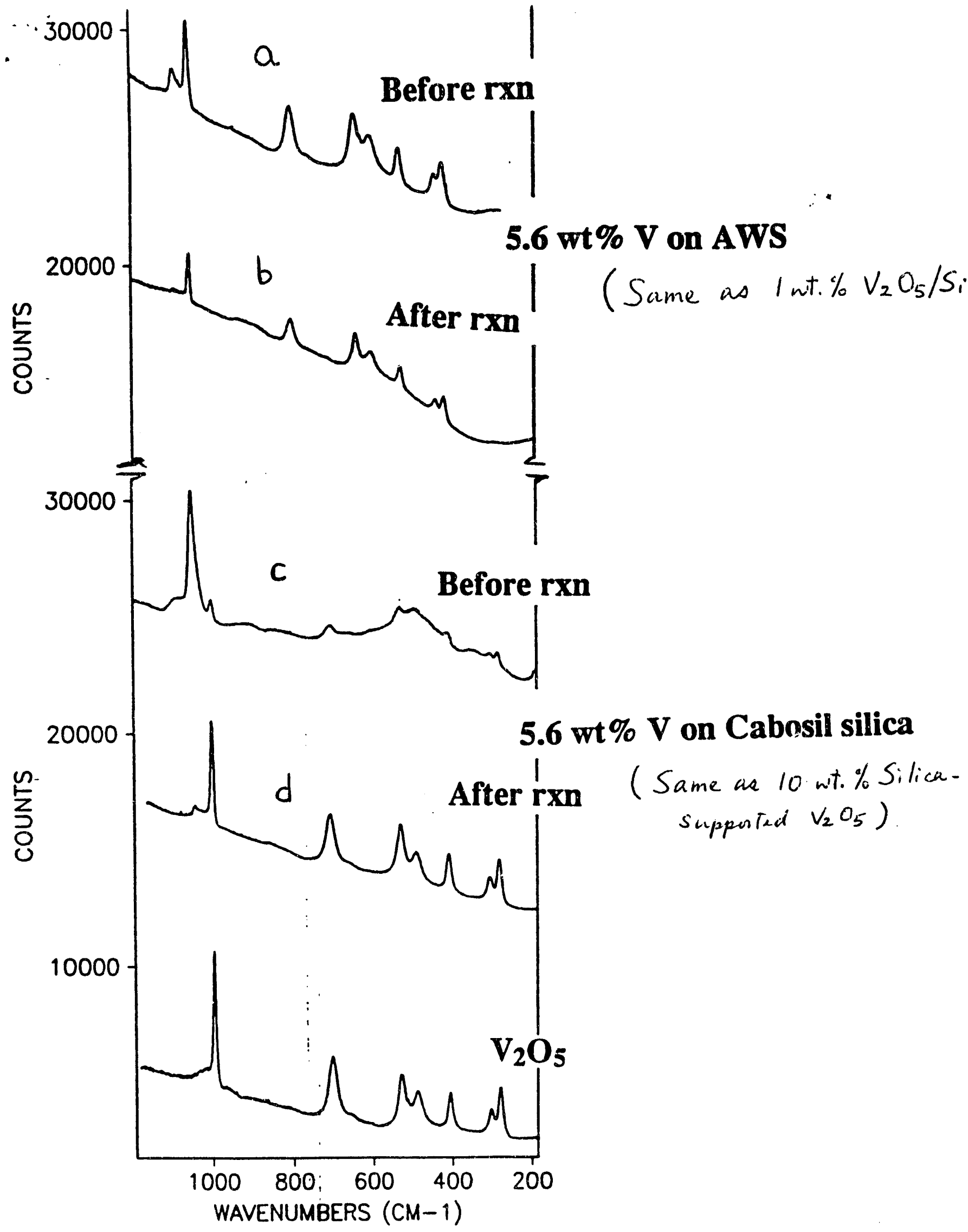

Fig. 4: Raman spectra of samples before and after reaction for the $10 \mathrm{wt} . \%$ $v_{2} 0_{5}{ }^{\prime} S_{i 0}$ samples. 


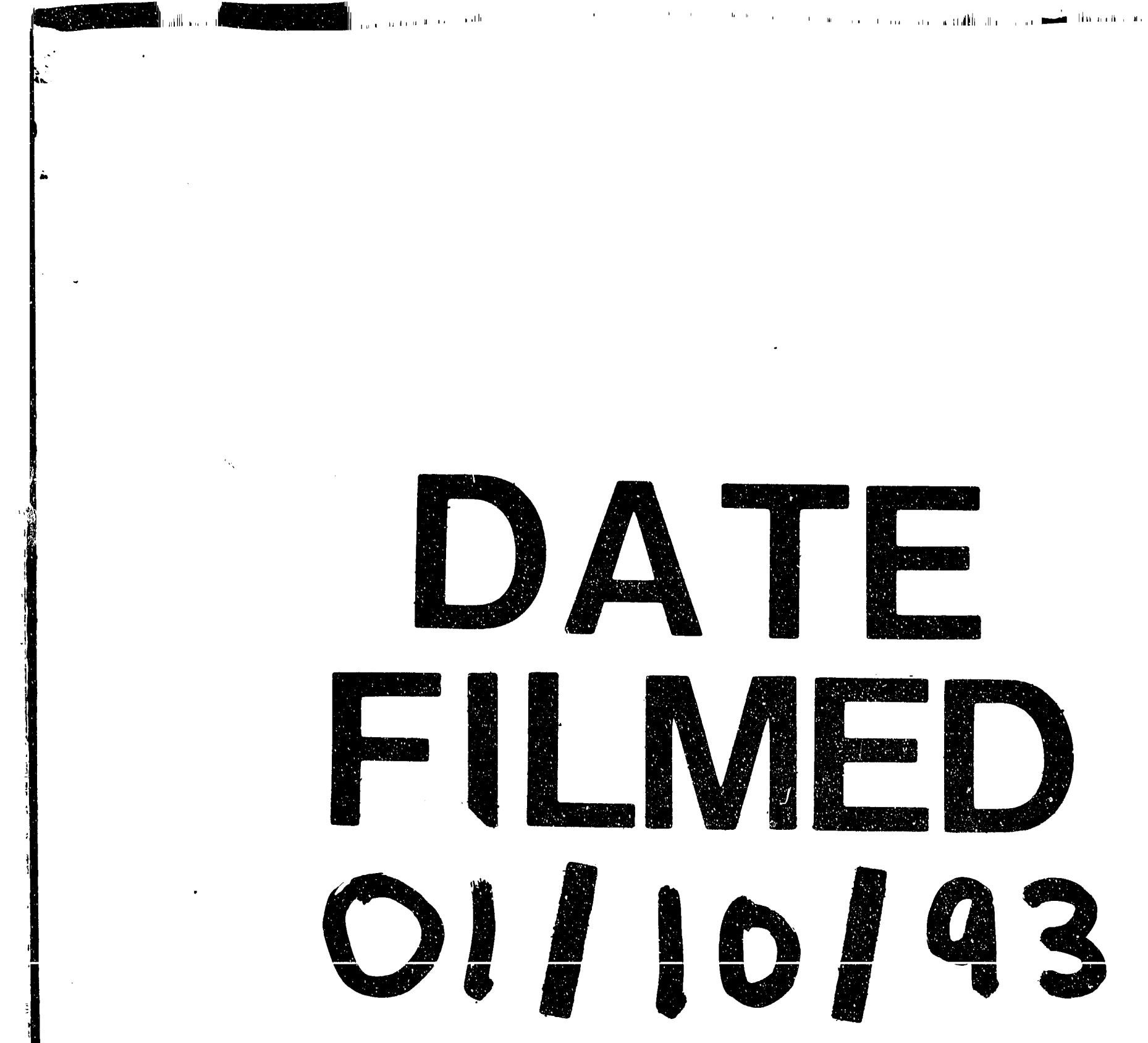




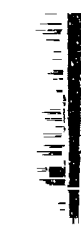

